\author{
Asian Journal of \\ Medical and Biological Research \\ ISSN 2411-4472 (Print) 2412-5571 (Online) \\ www.ebupress.com/journal/ajmbr
}

\title{
Article \\ Maternal factors of low birth weight babies in an antenatal care hospital in Bangladesh
}

Musammet Rasheda Begum $^{1 *}$ and Soma Chowdhury Biswas ${ }^{2}$

${ }^{1}$ Department of Agricultural Economics and Social Sciences, Chittagong Veterinary and Animal Sciences University, Khulshi, Chittagong-4225, Bangladesh

${ }^{2}$ Department of Statistics, University of Chittagong, Chittagong-4331, Bangladesh

*Corresponding author: Musammet Rasheda Begum, Associate Professor, Department of Agricultural Economics and Social Sciences, Chittagong Veterinary and Animal Sciences University, Khulshi, Chittagong4225, Bangladesh. Phone: +8801775770185; E-mail: rasustat@yahoo.com

Received: 11 September 2019/Accepted: 08 October 2019/ Published: 31 December 2019

\begin{abstract}
Low birth weight (LBW) has been considered as the strongest predictor of child morbidity and mortality. The goal of this study was to inspect the socio-demographics and nutritional status of mother and its impact on neonatal birth weight. A cross-sectional study was conducted among 85 mothers with third trimester's pregnancy period of age between 17 to 35 years in maternal health care centers at Chittagong, Bangladesh. Average age of mothers was $24 \pm 04$ years and age at marriage it was $18 \pm 03$ years. Height and MUAC of the respondents were $153 \pm 5.37 \mathrm{~cm}$ and $25.53 \pm 3.09 \mathrm{~cm}$ respectively. Half of participants suffered from anemia $(\mathrm{Hb}$ level $<11 \mathrm{~g} / \mathrm{dL}$ ). Average birth weight was $2759.7 \pm 561.42 \mathrm{~g}$. The preterm birth was $10.6 \%$ and about $22.35 \%$ babies delivered by $\mathrm{C}$ section. Twenty eight percent of offspring were born with low birth weight (LBW), among the LBW babies, $11.76 \%$ were born at home and $16.47 \%$ at hospital. Maternal height (AOR: $2.79 ; 95 \%$ CI: 1.02-8.44), Mid Upper Arm Circumference (MUAC) (AOR 2.73; 95\% CI 1.03-8.01) and gestational age (AOR 8.92, 95\% CI: 1.76-45.16) were significantly associated with LBW of babies after adjusting the education level of mothers. The proportion of LBW was not negligible which still national public health concern in Bangladesh. Proper nutrition and monitoring on gestational length might minimize small size babies.
\end{abstract}

Keywords: maternal factors; low birth weight; MUAC; preterm; Bangladesh

\section{Introduction}

Low birth weight (LBW) is typically the absolute most determinants of newborn child mortality (UNICEF, 2004). Low birth weight (LBW) defined as less than $2500 \mathrm{~g}$ at birth (WHO, 1992). In 2015, 20.5 million newborns, an estimated 14.6 per cent of all babies born globally that year, suffered from low birth weight (Christian et al., 2013). About half of the world underweight kids have born in South Asia (UNICEF, 2004; WHO, 2014). LBW babies die mainly in first years of their life because of malnutrition (Walden et al., 2007; Shahnawaz, 2014).

Bangladesh rapidly meets most of the millennium development goals, but malnutrition rate still remains unacceptably high (Rahman et al., 2016). National survey 2003-2004 reported about 36\% infants born with lower size in Bangladesh, where 29\% frequencies found in urban areas (BBS, 2005; Azimul et al., 2009). In National survey of 2015, the LBW rate was 22.6 percent (IPHN, 2017). Additionally, commonness of LBW is conflicting from 17\% to 25.5\% and inconclusive (Khan et al., 2018; Yasmeen and Azim, 2011). Besides, its determinants change crosswise over assorted settings and need examination with in various conditions (Hosain et al., 2006).

Previous research found that LBW is a multifactorial outcome (Karim et al., 2016). Maternal age, education and family income have been related to with LBW (Fall et al., 2015; Silvestrin et al., 2013; Wasunna and 
Mohammed, 2002). Mothers with low MUAC and pre pregnancy BMI are more likely to deliver small babies (Mohanty et al., 2006). In addition, antenatal hypertension, anemia and poor weight gain during pregnancy expand the danger of LBW (Badshah et al., 2008; Feresu et al., 2004). Obstetrical components of parity and gestational age likewise unequivocally connected with low birth weight (Hinkle et al., 2014; Voigt et al., 2004). In spite of the fact, indicators could be change among various settings and financial conditions.

Chittagong is the second largest city in Bangladesh. Many people have moved from rural area to the city and lead lower class life in city slums. They mostly took antenatal care from those types of low-cost maternity clinics. National study 2011 expressed most noteworthy recurrence (23\%) of low birth weight found at Chittagong division (Haque et al., 2015). According to existing literature, only one hospital based study was conducted in this setting which used only MUAC as hypothesized predictors of birth size (Ahmed et al., 2000). But, other possible determinants could be contributed to the detrimental outcome. Understanding on the prevalence of LBW and its potential risk factors would be the key for developing and designing interventions to reduce the events of $\mathrm{LBW}$.

\section{Materials and Methods}

\subsection{Study setting}

We conducted this study to know the events of LBW and its associated factors among mothers came to antenatal care clinic. We have selected one representative community clinic that provides low-cost services for pregnant women and children and located at the center of Chittagong city corporation Chittagong districts, $265 \mathrm{~km}$ from capital Dhaka. The total population of Chittagong district was 8,440,000 of 2011 census data (BBS, 2011). National survey 2011 stated highest rates (23\%) of poor birth size found at Chittagong division (Haque et al., 2015). Pregnant women who came to the clinic for regular health checkup invited to participate in this study.

\subsection{Procedures and participants}

The study was conducted in accordance with the declaration of Helsinki, 1964. The study was approved and reviewed department of Statistics, University of Chittagong. Ethical clearance obtained from data collecting institution (Approval no.: 01: 01/09/2015). Right to withdraw from the study at any time, without any precondition was maintained. Trained investigators explained the study objectives to the women.

Of a total of 105 women contacted in third trimester pregnancy period, only 85 women agreed to participate and the rest of the women who refused to participate, 19.05\% $(\mathrm{N}=20)$ due to lack of time or lack of interest in participating in the study. Pregnant mothers were asked, and written consent was obtained from 85 mothers after discussing the purpose, concealment, assured that this research will not be harmful for them. Data were collected with a pre-tested structured questionnaire in room of clinic beside the checkup room. Technicians of clinic assisted to collect data and require average 10 minutes for each participant. Response rate of the study was $80.95 \%$.

\subsection{Study variables}

We collected data on socio-demographic of pregnant women, gestational age, mother's age, mother's age at married, mother's education, maternal height, pre-pregnancy weight, family income, maternal parity, and nutritional parameters including mid-upper arm circumference (MUAC), body mass index (BMI), and hemoglobin $(\mathrm{Hb})$. We hypothesized that maternal age, education and family income, MUAC, pre pregnancy BMI, anemia and poor weight gain during pregnancy, parity and gestational age could be associated with LBW (Fall et al., 2015; Silvestrin et al., 2013; Wasunna and Mohammed, 2002; Mohanty et al., 2006; Badshah et al., 2008; Feresu et al., 2004; Hinkle et al., 2014; Voigt et al., 2004).

\subsection{Anthropometric measurement}

Height of women measured using portable Harpenden stadiometer (Holtain Ltd, London, UK) and categorized as $<151 \mathrm{~cm}$ and $\geq 151 \mathrm{~cm}$ according to Kitange (1994). Mid-upper arm circumference (MUAC) measured with Talc insertion tape and classified into $\leq 24 \mathrm{~cm}$ and $>24$ (WHO 1995). We denoted $<2500 \mathrm{gm}$ as low birth weight (LBW) and $\geq 2500 \mathrm{gm}$ or (2500-4200) gm as normal birth weight (WHO, 1992). According to Engle \& Kominiarek (2008) gestational age categorized as preterm ( $<37$ weeks) and term birth ( $\geq 37$ weeks). Data on maternal $\mathrm{Hb}$ concentration collected from lab report prescribed by doctors. We defined $\mathrm{Hb}$ level <11 g/dl as anemic and $\geq 11 \mathrm{~g} / \mathrm{dl}$ as normal or nonanemic (Shirima and Kinabo, 2005). 


\subsection{Statistical analysis}

Frequency distributions, descriptive analysis (mean, standard deviation (SD), range) were calculated for all variables. Multiple linear regression model was used with step wise backward selection method. All assumptions (independence, homoscedasticity, normality and linearity) of final model were checked by graphically and formal test. We used studentized residuals test to detect any outlier in response variable. Leverage test was used to know any outlier in predictors. Bivariate analysis performed to check the association between birth weight and other covariates. Multiple logistic regression analysis conducted to measure the effect of covariates on birth weight. We checked the final model with Hosmer and Lemeshow goodness of fit test statistic. We used statistical software SAS 9.3 and R 2.14.0 and, considered 5\% level of significance.

\section{Results}

\subsection{Characteristics of mothers and prevalence of $\mathbf{L B W}$}

Average age of participants was 24 years (SD 4 years). Maximum mothers $44(41.1 \%)$ belonged to age between 21 to 25 years. Mean age of marriage was 18 years (SD 3 years). One half (51.4\%) of the respondents get married at $\leq 18$ years old. Mean pre-pregnancy weight was $50.48 \mathrm{~kg}$ (SD $9.29 \mathrm{~kg}$ ). Illiterate or primary educated mothers comprised $19(22.35 \%)$ of participants. Only $14(13.1 \%)$ of respondents were employed.

Average height of the participant was $153 \mathrm{~cm}$ (SD $5.37 \mathrm{~cm}$ ) whereas 32.7\% (95\% CI: 23.9; 42.5) subjects were less than $151 \mathrm{~cm}$. According to the MUAC measurement, the average MUAC was $25.53 \mathrm{~cm}$ (SD $3.09 \mathrm{~cm})$ while $39.3 \%$ (95\% CI: 30.0; 49.2) mothers' was wasting, and 60.7\% was normal. Of the interviewed, 64 mothers gave the blood for $\mathrm{Hb}$ analysis. Half $(51.6 \%$; CI: 38.73; 64.25) of the them had the Hb level $<11 \mathrm{~g} / \mathrm{dL}$.

Average birth weight was $2759.7 \pm 561.42 \mathrm{~g}$. The preterm birth was $10.6 \%$ (95\% CI: 4.96; 19.15). About 22.35 $\%$ babies delivered by $\mathrm{C}$ section and $71.77 \%$ mothers admitted hospital for child-birth. Prevalence of LBW was $28.23 \%$ (95\% CI: 19.0; 39.04). Among the LBW babies, $11.76 \%$ were born at home and $16.47 \%$ at hospital.

\subsection{Multiple regression analysis}

The final model of multiple regression analysis contained the parameters of age, education, parity and gestational age. Age, education and gestational age were positively associated with birth weight but contemporary parity was negatively associated with birth weight. In general, a unit change of age, education level and gestational age corresponding to increases $75.4 \mathrm{gm}, 85.37 \mathrm{gm}$ and $88.66 \mathrm{gm}$ birth weight respectively (Table 1). On the contrary, if expect one more child then the probability of birth weight decreases $309.94 \mathrm{gm}$ (Table 1). After fitting the model all assumptions of the regression model was checked (Figure 1) and the model satisfies the normality, equality of the variance or homoscedasticity, independence of the residual and linearity of the model by the Shapiro-Wilk test, Levene test, Durbin Watson test and lack of fit test respectively. No outlier was found regarding response variable and predictors.

Table 1. Parameter estimates of LBW using multiple regression model.

\begin{tabular}{llll}
\hline Parameters & Estimate & Standard Error & Pr $>|\mathbf{t}|$ \\
\hline Intercept & -1073.1 & 1038.4 & 0.3046 \\
Age of mother (in years) & 75.3954 & 26.306 & 0.0053 \\
Education & 85.3657 & 39.5086 & 0.0338 \\
Parity & -309.94 & 115.243 & 0.0087 \\
Gestational age at birth (in week) & 88.6578 & 22.738 & 0.0002 \\
\hline
\end{tabular}

\subsection{Univariate analysis of influencing factors of birth weight (BW)}

We used chi-square test to examine the association between birth weight and other covariates (Table 2). When the cell frequency was less than 5, the Fisher Exact test was performed as alternative to chi-square test. A significant association $(\mathrm{P}=0.014)$ between birth weight and gestational age was observed. Marginal significant association found between birth weight and maternal height and MUAC. 
Table 2. Association between birth weight and other covariates of mothers in an antenatal care clinic, Chittagong, Bangladesh ( $\mathrm{N}=85)$.

\begin{tabular}{|c|c|c|c|c|}
\hline \multirow[t]{2}{*}{ Parameters } & \multicolumn{2}{|c|}{ Birth Weight } & \multirow[t]{2}{*}{ Chi-square } & \multirow[t]{2}{*}{ P-value } \\
\hline & $\begin{array}{l}\text { Low }(<2500 \mathrm{gm}) \\
N(\%)\end{array}$ & $\begin{array}{l}\text { Normal }(\geq 2500 \mathrm{gm}) \\
\text { N }(\%)\end{array}$ & & \\
\hline \multicolumn{5}{|l|}{ Age (in years) } \\
\hline$\leq 20$ & $6(7.06)$ & $15(17.65)$ & & $0.329^{\text {FET }}$ \\
\hline $21-25$ & $14(16.47)$ & $26(30.59)$ & & \\
\hline$>25$ & $4(4.71)$ & $20(23.53)$ & & \\
\hline \multicolumn{5}{|l|}{ Age at marriage (in years) } \\
\hline$\leq 18$ & $11(12.9)$ & $34(40)$ & 0.678 & 0.410 \\
\hline$>18$ & $13(15.3)$ & $27(31.8)$ & & \\
\hline \multicolumn{5}{|l|}{ Education } \\
\hline Illiterate & $2(2.35)$ & $5(5.88)$ & & $0.526^{\mathrm{FET}}$ \\
\hline Primary & $3(3.53)$ & $9(10.59)$ & & \\
\hline Secondary & $16(18.82)$ & $31(36.47)$ & & \\
\hline Higher secondary \& above & $3(3.53)$ & $16(18.82)$ & & \\
\hline \multicolumn{5}{|l|}{ Employment status } \\
\hline Employed & $3(3.53)$ & $9(10.59)$ & & $0.788^{\mathrm{FET}}$ \\
\hline Unemployed & $21(24.71)$ & $52(61.18)$ & & \\
\hline \multicolumn{5}{|l|}{ Height $(\mathbf{c m})$} \\
\hline$<151$ & $10(11.76)$ & $13(15.29)$ & 3.616 & $0.057^{\mathrm{MS}}$ \\
\hline$\geq 151$ & $14(16.47)$ & $48(56.47)$ & & \\
\hline \multicolumn{5}{|c|}{ Mid Upper Arm Circumference (MUAC) } \\
\hline$\leq 24$ & $13(15.29)$ & $19(22.35)$ & 3.888 & $0.049^{\mathrm{MS}}$ \\
\hline$>24$ & $11(12.94)$ & $42(49.41)$ & & \\
\hline \multicolumn{5}{|l|}{ Hemoglobin $(g / d L)(N=54)$} \\
\hline$<11$ & $4(7.41)$ & $26(48.15)$ & & $0.105^{\mathrm{FET}}$ \\
\hline$\geq 11$ & $8(14.81)$ & $16(29.63)$ & & \\
\hline \multicolumn{5}{|l|}{ Parity } \\
\hline Nulliparous & $11(12.94)$ & $23(27.06)$ & & $0.8450^{\text {FET }}$ \\
\hline Primiparous & $10(11.76)$ & $30(35.29)$ & & \\
\hline Multiparous & $3(3.53)$ & $8(9.41)$ & & \\
\hline \multicolumn{5}{|l|}{ Gestational age at birth } \\
\hline Preterm $(<37 \mathrm{w})$ & $6(7.06)$ & $4(4.71)$ & & $0.014^{* \mathrm{FET}}$ \\
\hline $\operatorname{Term}(\geq 37 \mathrm{w})$ & $18(21.18)$ & $57(67.06)$ & & \\
\hline
\end{tabular}

FET $=$ Fisher Exact Test; MS=Marginally significant * Significant at $\mathbf{P}<0.05$

\subsection{Multiple logistic regression analysis of influencing factors of low birth weight}

Parameter estimates from multiple logistic regression model was shown in Table 3. Maternal height, MUAC and gestational age were significantly associated with low birth weight of infants after adjusting the education. The probability of low birth weight was $2.79,2.73,8.92$ times higher for the respondents of height $<151 \mathrm{~cm}$, MUAC $\leq 24 \mathrm{~cm}$ and gestational age at birth $<37$ weeks compared to height $\geq 151 \mathrm{~cm}$, MUAC $>24$ and gestational age at birth $\geq 37$ weeks respectively. A Hosmer and Lemeshow test $(P=0.51)$ indicated that the model fit the data well. All the parameters of fitted model were significant tested by Likelihood ratio test by comparing null model and saturated model (Chi-square $=14.36$, P-value $=0.006$ ).

Table 3. Parameter estimates of low birth weight using multiple logistic regression model.

\begin{tabular}{|c|c|c|c|c|}
\hline Parameters & Estimate & Standard Error & P-value & OR $(95 \%$ CI $)$ \\
\hline Height of mother $<151 \mathrm{~cm}^{\mathrm{a}}$ & 1.026 & 0.565 & 0.034 & $2.79(1.02-8.44)$ \\
\hline MUAC $\leq 24 \mathrm{~cm}^{\mathrm{b}}$ & 1.004 & 0.549 & 0.027 & $2.73(1.03-8.01)$ \\
\hline Gestational age $<37 \mathrm{w}^{\mathrm{c}}$ & 2.188 & 0.828 & 0.008 & $8.92(1.76-45.16)$ \\
\hline Education below secondary ${ }^{\mathrm{d}}$ & 0.069 & 0.655 & 0.566 & $1.07(0.30-3.87)$ \\
\hline
\end{tabular}

${ }^{a}$ Height of $\geq 151 \mathrm{~cm}$ as reference or comparison group. ${ }^{\mathrm{b}} \mathrm{MUAC}>24 \mathrm{~cm}$ as reference or comparison group. ${ }^{\mathrm{c}}$ Gestational age $\geq 37$ weeks as reference or comparison group. ${ }^{\mathrm{d}}$ Secondary and above as reference or comparison group. 


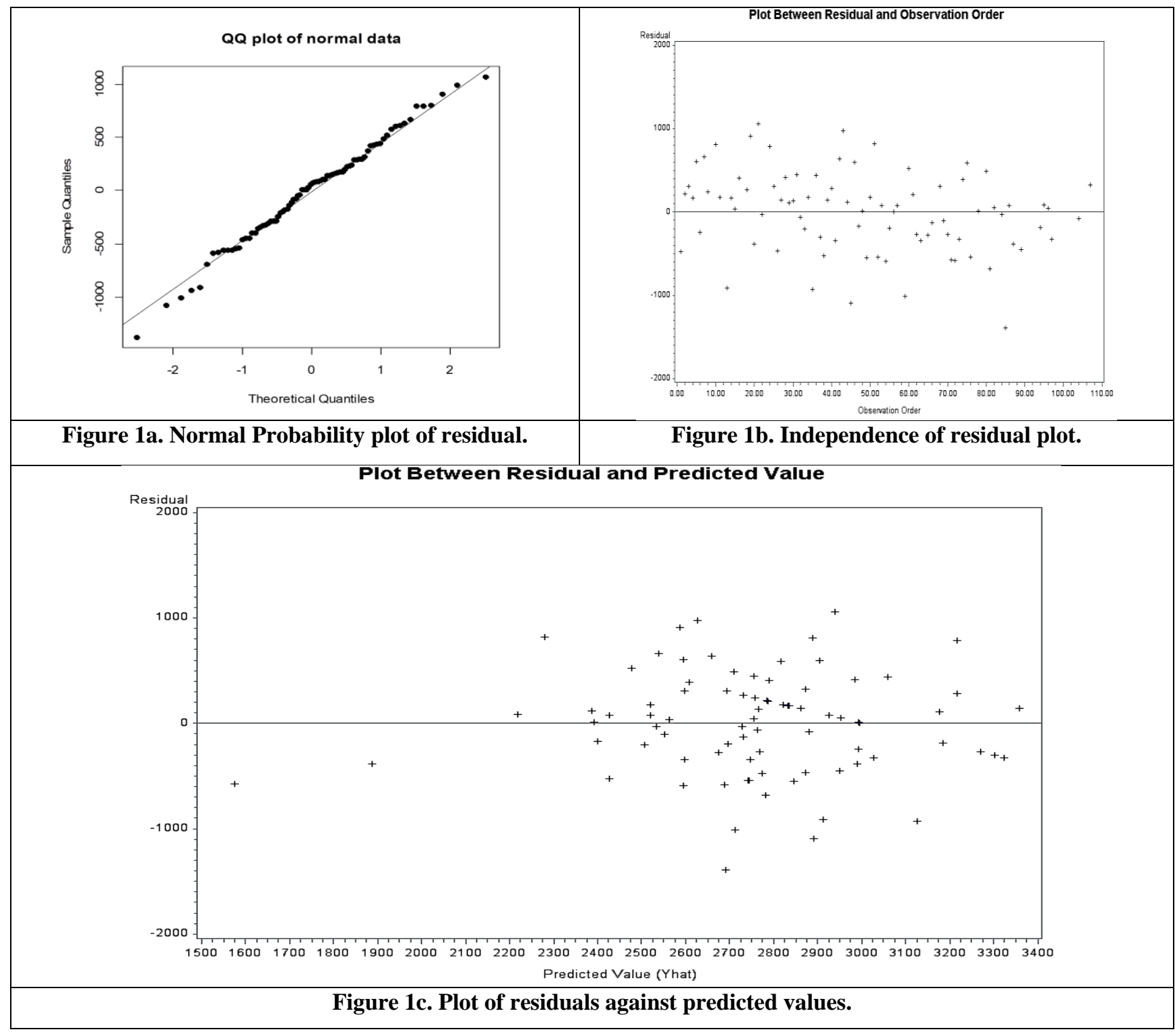

Figure 1. Normality, independence and homoscedasticity checked by using graphical method.

\section{Discussion}

This study explores the prevalence and determinants of LBW among low income city mothers. Findings showed that twenty eight percent of neonates were smaller in weight. Maternal height, gestational age and MUAC were associated with this birth outcome.

National survey 2011 found 23\% LBW in the Chittagong District (Haque et al., 2015). This study revealed slightly higher prevalence. It was similar $28.3 \%$ in demographic Surveillance of Ethiopia and $27 \%$ in Nepal (Assefa et al., 2012; Sharma et al., 2015). Our higher prevalence might be due to lower socio-economy of the participants. About half of our participants came from the family income below 10000 BD TK. Money is key to get access to facilities, food and services may lead mothers fit for child birth.

Recent reviews have suggested that mother's nutritional status positively affected LBW (da Silva Lopes $e t$ al., 2017). Present study shows that the risk of LBW was 2.73 times higher for MUAC $<=24 \mathrm{~cm}$ than $>24 \mathrm{~cm}$. Sebayang et al. (2012) found that MUAC was closely associated with LBW among Indonesian babies. Similar result shown among the newborn in a materninity hospital of Zibabwe (Feresu et al., 2015). Nutritional management of mother during pregnancy has a strong role to reduce the LBW (Ramakrishnan, 2004). Research in Bangladesh noted LBW as determinants of malnutrition of under-five children (Rahman et al., 2016). Nutritional care on pregnant mother can lower LBW as well as malnutrition of under- five children in this area. Research in few Nordic countries has shown that maternal height was significantly associated with birth weight (Zhang et al., 2015). We found 2.79 times higher LBW in the mothers height of $\langle=151 \mathrm{~cm}$ then $>151 \mathrm{~cm}$ in our investigation. Similar finding was observed in Sudanese newborn (Elshibly and Schmalisch, 2008). Although, 
Veena et al. (2004) pointed out that infant size is influenced by paternal rather than maternal height while Voigt et al. (2004) stated that influence of paternal characteristics is negligible. Shorter women may have a small uterus size which may limiting fetal growth (Zhang et al. 2007) or height reflect a nutritional condition indirectly effect on fetal growth in uterus (Subramanian et al. 2009).

Investigation showed that Bangladesh is one of leading countries for small-for-gestational-age infants (Lee et al. 2013). We observed low birth weight was 8.92 times higher for Gestational age at birth $<=37$ weeks than $>37$ weeks. Similarly gestational age considered as a significant contributor to birth weight in in the United States (Donahue, 2010). Elshibly and Schmalisch (2008) found that gestational age and LBW was significantly associated.

Several studies have reported increased risks of low birth weight (LBW) among offspring of adolescent mother (Chen et al., 2007; Haldre et al., 2007). We observed an association of maternal age with birth weight of infant. Another study of Britto et al. (2013) showed that age of less than 20 years was more likely to have LBW baby than $\geq 20$ years. Another study was found that the birth weights are different with different age (Tabrizi and Saraswathi, 2012). In this study, more than half 55 (51.4\%) of the respondents were married while as $\leq 18 \mathrm{y}$ old. Many studies showed that children of young mother have an increased risk of low birth weight and preterm birth (Fall et al., 2015).

Socio-economic variables have long been known to influence the outcome at birth (Elshibly and Schmalisch, 2008). We found a positive association of maternal education with LBW of child. In Bangladesh, maternal formal education led to decrease in child stunting (Semba et al., 2008). Another study by Rahman et al. (2016) shown higher education of mother strongly associated with LBW of babies in a nationally represented survey in Bangladesh. Education acts as gate way for awareness leads mother to cope up the challenges of pregnancy resulting better outcome. Parity was negatively associated with birth weight in our study. Previous studies found lowest birth weights among infants of nulliparous women (Shah, 2010; Melve et al., 2002; Pedersen et al., 2007). Hinkle et al. (2014) noted that birth weight continued to increase minimally up to third parity. Our study was not free from limitations. This hospital based study may narrow its generalization. All participants were not educated might left some information bias.

\section{Conclusions}

Maternal height, MUAC and gestational age were major determinants of birth size. Improving and monitoring the nutritional status of women particularity pregnant women would lower the incident. Results of this study suggest future study to identify risk factors of pregnancy malnutrition and premature delivery. We expected our findings will help decision makers to design and implement policy to reduce incidence of LBW babies in similar settings of Bangladesh and other developing countries.

\section{Acknowledgements}

The authors are very grateful to the study participants and head of the health care center to access the work. All health care promoters were acknowledged for their cooperation during collection of necessary information from participants.

\section{Conflict of interest}

None to declare.

\section{References}

Ahmed FU, E Karim and SN Bhuiyan, 2000. Mid-arm circumference at birth as predictor of low birth weight and neonatal mortality. J. Biol. Sci., 32: 487-493.

Assefa N, Y Berhane and A Worku, 2012. Wealth status, mid upper arm circumference (MUAC) and antenatal care (ANC) are determinants for low birth weight in Kersa, Ethiopia. PLoS ONE, 7: e39957.

Azimul S, A Matin, J Shabnam, S Shamianaz and M Bannerje, 2009. Maternal factors affecting low birth weight in urban area of Bangladesh. Journal of Dhaka Medical College, 18: 64-69.

Badshah S, L Mason, K Mckelvie, R Payne and PJ Lisboa, 2008. Risk Factors for low birth weight in the public-hospitals at Peshawar, NWFP-Pakistan. BMC Public Health, 8: 1-10.

BBS, 2005. Bangladesh Bureau of Statistics. National Low Birth Weight Survey of Bangladesh 2003-2004. Planning division, Ministry of Planning, Government of the People's Republic of Bangladesh.

BBS, 2011. Bangladesh Bureau of Statistics. Population and Housing Census. Bangladesh Bureau of Statistics; 2015. Available from: http://www.citypopulation.de/Bangladesh-Mun.html 
Britto RPdA, TMT Florêncio, AA Benedito Silva, R Sesso, JC Cavalcante and AL Sawaya, 2013. Influence of Maternal Height and Weight on Low Birth Weight: A Cross-Sectional Study in Poor Communities of Northeastern Brazil. PLoS ONE, 8: e80159.

Chen XK, SW Wen, N Fleming, K Demissie, GG Rhoads and M Walker, 2007. Teenage pregnancy and adverse birth outcomes: a large population based retrospective cohort study. Int. J. Epidemiol., 36: 368-373.

Christian P, SE Lee, M Donahue Angel, LS Adair, SE Arifeen, P Ashorn, FC Barros, CH Fall , WW Fawzi, W Hao, G Hu, JH Humphrey, L Huybregts, CV Joglekar, SK Kariuki, P Kolsteren, GV Krishnaveni, E Liu, R Martorell, D Osrin, LA Persson, U Ramakrishnan, L Richter, D Roberfroid, A Sania, FO Ter Kuile, J Tielsch, CG Victora, CS Yajnik, H Yan, L Zeng and RE Black, 2013. Risk of childhood undernutrition related to small-for-gestational age and preterm birth in low- and middle-income countries. Int. J. Epidemiol., 42: 1340-55.

da Silva Lopes K, E Ota, P Shakya, A Dagvadorj, OO Balogun, JP Peña-Rosas, LM De-Regil and R Mori, 2017. Effects of nutrition interventions during pregnancy on low birth weight: an overview of systematic reviews. BMJ Global Health, 2: e000389.

Donahue SMA, KP Kleinman, MW Gillman and E Oken, 2010. Trends in birth weight and gestational length among singleton term births in the United States 1990-2005. Obstet. Gynecol., 115: 357-364.

Elshibly EM and G Schmalisch, 2008. The effect of maternal anthropometric characteristics and social factors on gestational age and birth weight in Sudanese newborn infants. BMC Public Health, 8: 244.

Engle WA and MA Kominiarek, 2008. Late Preterm Infants, Early Term Infants, and Timing of Elective Deliveries. Clin. Perinatol., 35: 325-341.

Fall CHD, HS Sachdev, C Osmond, MCR Mendez, C Victora, R Martorell, AD Stein, S Sinha, N Tandon, L Adair, I Bas, S Norris and LM Richter, 2015. Association between maternal age at childbirth and child and adult outcomes in the offspring: a prospective study in five low-income and middle-income countries (COHORTS collaboration). Lancet Glob. Health, 3: e366-77

Feresu SA, SD Harlow and GB Woelk, 2015. Risk Factors for Low Birthweight in Zimbabwean Women: A Secondary Data Analysis. PLoS ONE, 10: e0129705.

Feresu SA, SD Harlow, K Welch and BW Gillespie, 2004. Incidence of and sociodemographic risk factors for stillbirth, preterm birth and low birth weight among Zimbabwean women. Harare, Zimbabwe. Pediatric and Prenatal Epidemiology, 18: 154-163.

Haldre K, K Rahu, H Karro and M Rahu, 2007. Is a poor pregnancy outcome related to young maternal age? A study of teenagers in Estonia during the period of major socio-economic changes (from 1992 to 2002). European Journal of Obstetrics, Gynecology, and Reproductive Biology, 131: 45-51.

Haque SMR, S Tisha and N Huq, 2015. Low Birth Weight Accompanying Less Antenatal Care in Bangladesh with Substantial Divisional Variation: Evidence from BDHS - 2011. Public Health Research, 5: 184-191.

Hinkle SN, PS Albert, P Mendola, LA Sjaarda, E Yeung, NS Boghossian and SK Laughon, 2014. The association between parity and birthweight in a longitudinal consecutive pregnancy cohort. Paediatr. Perinat. Epidemiol., 28: 106-115.

Hosain GMM, N Chatterjee, A Begum and SC Saha, 2006. Factors Associated with Low Birthweight in Rural Bangladesh. Journal of Tropical Pediatrics, 52: 87-91.

IPHN, 2017. Institute of Public Health Nutrition, National Low Birth Weight Survey 2015, Directorate General of Health Services, Ministry of Health \& Family Welfare, Government of Bangladesh, http://ssmfbd.org/images/pdf/national_low_birth_weight\%20_survey.pdf

Janjua ZN, E Delzell and RR Larson, 2008. Deteminats of low birth weight in Urban Pakistan. In: Nutrition PH, editor. Birmingham Al, USA: UAB.EDU.

Karim MR, MNI Mondal, MM Rana, H Karmaker, P Bharati and MG Hossain, 2016. Child birth weight in Bangladesh 257 maternal factors are important predictors of low birth weight: evidence from Bangladesh demographic \& health survey-2011. Mal. J. Nutr., 22: 257-265.

Khan JR, MM Islam, N Awan and O Muurlink, 2018. Analysis of low birth weight and its co-variants in Bangladesh based on a sub-sample from nationally representative survey. BMC Pediatrics, 18:100.

Kitange D, 1993. "Adolescent health and nutrition." Proceedings of the National Maternal Nutrition Workshop, January 11-15, pp. 145.

Lee AC, J Katz, H Blencowe, S Cousens, N Kozuki, JP Vogel, L Adair, AH Baqui, ZA Bhutta, LE Caulfield, P Christian, SE Clarke, M Ezzati, W Fawzi, R Gonzalez, L Huybregts, S Kariuki, P Kolsteren, J Lusingu, T Marchant, M Merialdi, A Mongkolchati, LC Mullany, J Ndirangu, ML Newell, JK Nien, D Osrin, D Roberfroid, HE Rosen, A Sania, MF Silveira, J Tielsch, A Vaidya, BA Willey, JE Lawn, RE Black and CHERG SGA-Preterm Birth Working Group, 2013. National and regional estimates of term and preterm 
babies born small for gestational age in 138 low-income and middle-income countries in 2010. Lancet Glob. Health, 1: e26-e36.

Melve KK, R Skjaerven and N Oyen, 2002. Families with a perinatal death: is there an association between the loss and the birthweight of surviving siblings? Paediatr. Perinat. Ep., 16: 23-32.

Mohanty C, R Prasad, A Srikanth Reddy, JK Ghosh, TB Singh and BK Das, 2006. Maternal Anthropometry as Predictors of Low Birth Weight. J. Trop. Pediatr., 52: 24-29.

Pedersen CB, Y Sun, M Vestergaard, J Olsen and O Basso, 2007. Assessing fetal growth impairments based on family data as a tool for identifying high-risk babies. An example with neonatal mortality. BMC Pregnancy and Childbirth, 7: 28.

Rahman MS, T Howlader, MS Masud and ML Rahman, 2016. Association of low-birth weight with malnutrition in children under five years in Bangladesh: do mother's education, socio-economic status, and birth interval matter? PLoS ONE, 11: e0157814.

Ramakrishnan U, 2004. Nutrition and low birth weight: from research to practice. Am. J. Clin. Nutr., 79: 17-21.

Sebayang SK, MJ Dibley, PJ Kelly, AV Shankar, AH Shankar and SUMMIT Study Group, 2012. Determinants of low birthweight, small-for-gestational-age and preterm birth in Lombok, Indonesia: analyses of the birth weight cohort of the SUMMIT trial. Trop. Med. Int. Health, 17: 938-950.

Shah PS, 2010. Parity and low birth weight and preterm birth: a systematic review and meta-analyses. Acta Obstetricia et Gynecologica Scandinavica, 89: 862-875.

Shahnawaz K, SK Choudhary, G Sarker, P Das, R Pal and L Kumar, 2014. Association between maternal sociodemographic factors and low birth weight newborn in a rural area of Bihar, India. South East Asia Journal of Public Health, 4: 30-34.

Sharma SR, S Giri, U Timalsina, SS Bhandari, B Basyal, K Wagle and L Shrestha, 2015. Low birth weight at term and its determinants in a tertiary hospital of Nepal: a case-control study. PLoS ONE, 10: e0123962.

Shirima CP and JL Kinabo, 2005. Nutritional status and birth outcomes of adolescent pregnant girls in Morogoro, Coast, and Dar es Salaam regions, Tanzania. Nutrition, 21:32-38.

Silvestrin S, CH Silva, VN Hirakata, AA Goldani, PP Silveira and MZ Goldani, 2013. Maternal education level and low birth weight: a meta-analysis. J. Pediatr. (Rio J), 89: 339-345.

Semba RD, S Pee, K Sun, M Sari, N Akhter and MW Bloem, 2008. Effect of paternal formal education on risk of child stunning in Indonesis and Bangladesh: a cross-sectional study. The Lancet, 371: 322-328.

Subramanian SV, LK Ackerson, G Davey Smith and NA John, 2009. Association of maternal height with child mortality, anthropometric failure, and anemia in India. Jama, 301: 1691-701.

Tabrizi FM and G Saraswathi, 2012. Maternal anthropometric measurements and other factors: relation with birth weight of neonates. Nutr. Res. Pract., 6: 132-137.

UNICEF, 2004. United Nations Children's Fund, World Health Organization. Low birth weight: country, regional and global estimates. New York: UNICEF. https://www.unicef.org/publications/files/low_ birthweight_from_EY.pdf.

Veena SR, K Kumaran, MN Swarnagowri, MN Jayakumar, SD Leary, CE Stein, VA Cox and CH Fall, 2004. Intergenerational effects on size at birth in South India. Paediatr. Perinat. Epidemiol., 18: 361-370.

Voigt M, G Heineck and V Hesse, 2004. The relationship between maternal characteristics, birth weight and pre-term delivery: evidence from Germany at the end of the 20th century. Econ. Hum. Biol., 2: 265-280.

Walden RV, SC Taylor, NI Hansen, WK Poole, BJ Stoll, D Abuelo and BR Vohr, 2007. Major congenital anomalies place extremely low birth weight infants at higher risk for poor growth and developmental outcomes. Pediatrics, 120: e1512-9.

Wasunna A and K Mohammed, 2002. Low birthweight babies: sociodemographic and obstetric characteristics of adolescent mothers at Kenyatta National Hospital, Nairobi. East. Afr. Med. J., 79: 543-546.

WHO, 1992. International statistical classification of diseases and related health problems. 10 Revision. Geneva: World Health Organization.

WHO, 1995. Physical status: the use and interpretation of anthropometry. Technical report series 854. Geneva: World Health Organisation, p. 854.

WHO, 2014. World Health Assembly WHA Global Nutrition Targets 2025; Low birth weight policy brief, Geneva: World Health Organisation; 2014. (http://www.who.int/nutrition/topics/globaltargets_ lowbirthweight_policybrief.pdf).

Yasmeen S and E Azim, 2011. Status of low birth weight at a tertiary level hospital in Bangladesh for a selected period of time. South East Asia Journal of Public Health. 1: 24-27. 
Zhang G, J Bacelis, C Lengyel, K Teramo, M Hallman, Helgeland Q, S Johansson, V Myhre R Sengpiel, PR Njølstad, B Jacobsson and L Muglia, 2015. Assessing the causal relationship of maternal height on birth size and gestational age at birth: a mendelian randomization analysis. PLoS Med., 12: e1001865.

Zhang X, S Cnattingius, RW Platt, KS Joseph and MS Kramer, 2007. Are babies born to short, primiparous, or thin mothers "normally" or "abnormally" small? J. Pediatr., 150: 603-607.e3. 